\title{
A DESTERRITORIALIZAÇÃO CAUSADA PELA VIOLÊNCIA BIOÉTNICA E OS PESCADORES ARTESANAIS DA BAÍA DE GUANABARA
}

\section{THE DETERRITORIALIZATION CAUSED BY BIOETHINIC VIOLENCE AND ARTISAN FISHERS IN BAIA DE GUANABARA}

\section{Cesar Bernardo Ferreira}

cesarbiologo@hotmail.com

Doutor em Humanidades, Culturas e Artes, Universidade do Grande Rio Professor José de Souza Herdy (UNIGRANRIO), Docente da Secretaria Estadual de Educação do Estado do Rio de Janeiro (SEEDUC).

ORCID: https://orcid.org/0000-0002-2304-495X

\section{Cleonice Puggian}

cleopuggian@gmail.com

Doutora em Educação (Universidade de Cambridge, Inglaterra), Docente da Universidade do Estado do Rio de Janeiro (UERJ)

ORCID: https://orcid.org/0000-0002-8122-2953

\section{RESUMO}

Este artigo apresenta os resultados de uma pesquisa sobre violência envolvendo os pescadores artesanais da baía de Guanabara, Rio de Janeiro. Examina como essa violência interfere no cotidiano desses trabalhadores, pois o cenário em que acontecem as violências é particularizado pela ocupação do espaço por grandes empreendimentos industriais, como a indústria do petróleo. Quanto aos aspectos metodológicos da pesquisa, optou-se pela metodologia etnográfica de cunho qualitativo através de trabalhos de campo (período de 2017 a 2019). Os instrumentos de coleta de dados foram a observação participante e a entrevista etnográfica, que foram gravadas em áudio e transcritas posteriormente por meio da tematização dos registros de campo e da narrativa dos participantes. Foram entrevistados ao todo 20 pescadores artesanais que atuam na baía de Guanabara. Para garantir a integridade e anonimato dos pescadores artesanais entrevistados, dei-lhes pseudônimos, para que que seus nomes verdadeiros não fossem revelados. Os resultados da presente pesquisa apontam para diversos casos de pescadores artesanais vitimados por armas de fogo oriundos dos agentes de segurança das plataformas e demais edificações da indústria petroquímica, com ênfase a Petrobras. Há ainda, vários relatos de pescadores vítimas de insultos verbais, cárcere privado, ameaças de morte, tortura, mutilações, omissão do Estado e prejuízos financeiros.

Palavras-chave: pescadores artesanais; Baía de Guanabara; violência; conflitos territoriais; violência bioétnica.

\section{ABSTRACT}

This article presents the results of a research on violence involving artisanal fishermen from Guanabara Bay, Rio de Janeiro. It examines how this violence 
interferes in the daily lives of these workers, as the scenario in which violence occurs is particularized by the occupation of space by large industrial enterprises, such as the oil industry. As for the methodological aspects of the research, we opted for the qualitative ethnographic methodology through fieldwork (period from 2017 to 2019). The instruments of data collection were participant observation and ethnographic interview, which were recorded in audio and later transcribed through the theme of the field records and the participants' narrative. A total of 20 artisanal fishermen who work in Guanabara Bay were interviewed. To guarantee the integrity and anonymity of the artisanal fishermen interviewed, I gave them pseudonyms, so that their real names would not be revealed. The results of the present research point to several cases of artisanal fishermen victimized by firearms from the security agents of the platforms and other buildings in the petrochemical industry, with emphasis on Petrobras. There are also several reports of fishermen victims of verbal abuse, private prison, death threats, torture, mutilation, omission by the State and financial losses.

Keywords: artisanal fishermen; Guanabara's Bay; violence; territorial conflicts; bioethical violence.

\section{INTRODUÇÃO}

Neste artigo apresento uma análise das experiências envolvendo casos de violência vividos por pescadores artesanais na baía de Guanabara, estado do Rio de Janeiro, tendo a Indústria do Petróleo, como o principal ator desse fenômeno social. A questão norteadora foi: quais são os casos de violência enfrentados pelos pescadores artesanais das colônias de pescadores da baía de Guanabara durante a execução do seu trabalho?

Os pescadores artesanais possuem uma íntima relação com o meio ambiente. Sua organização social é pautada em tradições estabelecidas ao longo de séculos. Seu modo de vida é baseado na dependência do que é extraído do ambiente natural, podendo ser considerada uma "simbiose" entre o gênero Homo e o mar. Esses povos são detentores do saber e do saber fazer para a sobrevivência no ambiente natural onde estão inseridos, pois seus estilos de vida, tradições, economia e cultura dependem diretamente do delicado equilíbrio do ambiente marinho para existir.

A questão que norteia esta pesquisa é verificar como as experiências envolvendo violência interferem no cotidiano desses homens e mulheres, frente ao processo de desterritorialização, de apoderamento do território pelo capital, sob diversas configurações, o processo de degradação identitário, cultural e social resultantes das alterações impostas ao modo de vida dessas comunidades tradicionais.

Os empreendimentos implementados ao longo dos anos no entorno da baía de Guanabara destroem os ecossistemas prejudicando 
economicamente e até impedindo o trabalho dos pescadores. Também, excluem os pescadores dos locais onde existem os peixes de maior valor econômico, gerando as áreas de exclusão pesqueira (CHAVES, 2011). Isto é causado principalmente pela atividade petroquímica, que nas últimas décadas tem realizado a instalação ostensiva de ductos e terminais. Existem outros atores atuantes nas áreas de exclusão pesqueira, como as forças armadas, com os aquartelamentos e fortes, zonas portuárias e aeroportuárias, aterros sanitários, e até mesmo as áreas de proteção ambiental, como é o caso da APA Guapimirim e da estação ecológica da Guanabara, locais onde é proibido pescar e coletar animais e vegetais.

Segundo Amador (2001), o pescador artesanal é o profissional que mais sente os impactos das alterações ambientais. O autor descreve a baía de Guanabara durante o período de colonização do Brasil, como uma baía com inúmeros cardumes, diversos tipos de moluscos, como ostras e mexilhões, assim como os crustáceos, fartos à época. Menciona também o manguezal, berçário natural de quase toda fauna local. Era o ambiente perfeito para os pescadores e coletores artesanais, pois era a garantia de sua subsistência.

Diversos autores das ciências sociais e ambientais, abrangendo a Ecologia e a Geografia Política, dissertam a respeito dos conflitos ambientais, no Brasil e no mundo, devido ao processo progressivo da disputa por território, envolvendo grandes empresas e as comunidades tradicionais (FUKS, 2001; MARTINEZ-ALIER, 1997; ACSELRAD, 2004, 2009; LITTLE, 2004; HERCULANO; PACHECO, 2006; PELLOW, 2006; PORTO, 2007; ZHOURI; LASCHEFSKI, 2010). O crescimento das produções intelectuais a respeito dessa temática é proporcional ao processo de globalização imposto pelo sistema capitalista, cujo olhar economicista é elencado por fundamentações produtivistas e consumistas, cujos modelos de execução industrial vão na contramão do respeito à vida, pouco se importando com a cultura e tradições dos povos, assim como a interação vivida entre homem/ambiente (MAIA, 2014).

Após diversos acidentes ambientais causados pela indústria petroquímica, os quais atingiram diretamente os pescadores artesanais, principalmente o do ano de $2000^{1}$, foram criados alguns movimentos de luta e resistência às injustiças ambientais na região. Esses movimentos, realizados por homens e mulheres das colônias de pescadores da baía de Guanabara, exigem uma mudança drástica da exploração desordenada do espaço geográfico da baía. São impactos que impossibilitam o pescador de exercer tranquilamente o seu trabalho, assim como alteram o ciclo biológico do ambiente, transformando o cenário natural. Com a diminuição do pescado, a limitação do território e a precariedade do trabalho, o pescador se vê em um cenário de intensa injustiça ambiental (ROSA et al., 2014).

Como elucida Acselrad (2004), os conflitos ambientais são, portanto, aqueles envolvendo grupos sociais com modos diferenciados de 
apropriação, uso e significação do território, tendo origem quando ao menos um dos grupos tem a continuidade das formas sociais de apropriação do meio que desenvolvem ameaçadas por impactos indesejáveis - transmitidos pelo solo, água, ar ou sistemas vivos decorrentes do exercício das práticas de outros grupos.

Por se localizar em uma região costeira, com intensa atividade antropogênica, a baía é suscetível a impactos, devido às diversas fontes de poluição, como os inúmeros aterros, dragagens, vazamentos de óleo, esgoto doméstico e industrial, sendo considerada a baía mais dragada do Brasil (AMADOR, 1997; VALENTIN et al., 1999). O esgoto doméstico lançado nas águas da baía corresponde a um volume de 415 toneladas por dia, 78 toneladas vêm de seus afluentes, causando alterações químicas e biológicas, tanto na água do mar, quanto nos manguezais.

Portanto, não podemos limitar a violência apenas sob o aspecto criminal que está qualificado no Código Penal brasileiro. Existem vários tipos de violências que afligem a sociedade, como as violências contra os grupos chamados de "minorias sociais", como negros, índios, homossexuais, nordestinos e povos tradicionais, como é o caso dos pescadores artesanais da baía de Guanabara.

Para muitos pesquisadores, a violência é um fenômeno social. Ela perpassa o cotidiano social sob muitas facetas, afetando as relações intersociais de forma complexa, em que geralmente extrapõe-se a contemporaneidade política, através de seus impactos na comunidade. "A violência possui ligações profundas com a desigualdade entre as classes e a exclusão social [...] fortalecimento das políticas sociais e da garantia de direitos" (SILVA, 2005, p. 20).

A seguir falarei sobre os aspectos metodológicos da pesquisa e a metodologia utilizada e os caminhos que nos levaram a alcançar os objetivos propostos, apesar das limitações e da própria dificuldade e periculosidade da imersão no universo conflagrado em que os acontecimentos estão inseridos. Todavia, tal fato, não pormenoriza as conclusões obtidas, mas sim reafirma o quanto os pescadores e demais moradores estão expostos aos problemas relativos a segurança pública na metrópole em que vivemos.

\section{A VIOLÊNCIA NA BAÍA DE GUANABARA E OS PESCADORES ARTESANAIS}

A violência na região da baía de Guanabara se manifesta de diversas formas para as comunidades tradicionais, coletiva ou individualmente, através dos conflitos territoriais que alteram o modo de vida desses povos, além de modificarem a arquitetura nativa dos ecossistemas dessa baía. A violência histórica nessa região é causadora de privações dos direitos socioambientais ${ }^{2}$ dos pescadores artesanais, ao gerar na região 
da baía degradações ambientais, como poluição, desmatamentos, além do aumento da sensação de insegurança por se trabalhar num território conflagrado pelas desigualdades.

Nas duas últimas décadas do século XX, as questões relacionadas aos problemas ambientais alcançaram a esfera global, sensibilizando a sociedade civil organizada em quase todas as regiões metropolitanas do mundo. A expansão urbana se perfaz no papel de um dos maiores vilões geradores de problemas ambientais, pela destruição do ambiente natural, do qual diversas comunidades tradicionais dependem para a sua subsistência.

De acordo com a Comissão Nacional de Povos e Comunidades Tradicionais, a Lei que regula a política nacional das Comunidades Tradicionais, que engloba tanto os pescadores artesanais, quanto as comunidades quilombolas, ribeirinhas, indígenas, caiçaras, caboclos, as coletoras artesanais e as quebradeiras de coco de babaçu, além de outros grupos étnicos, é a 6.040/07 (BRASIL, 2007). As comunidades tradicionais possuem um sentimento de territoriedade e pertencimento bastante definido, pois sua primeira reinvindicação é com relação ao direito à terra, cujo propósito é permitir a realização de todas as tradições referentes aos valores específicos de cada comunidade tradicional.

O aumento da violência e, consequentemente, a queda da sensação de segurança pelos pescadores, devido aos diversos conflitos envolvendo o uso do território na baía de Guanabara, levaram esses povos a se organizarem-se através de ações coletivas para o enfrentamento dessa situação. A postura de resistência adotada pelos pescadores justifica-se pela mudança de comportamento imposta e esses povos, devido à violência e ao medo, acarretando mudanças na arquitetura natural da baía, interferindo no cotidiano do seu local de trabalho (CALDEIRA, 2000).

A violência e o medo são questões importantes que se manifestam de diversas formas em todos os segmentos sociais, acometendo com maior intensidade as classes menos favorecidas, principalmente aqueles que moram em comunidades carentes, como as favelas, ou então, as que residem em comunidades tradicionais, como os povos caiçaras.

\section{MATERIAIS E MÉTODOS: A ÁREA DE ESTUDO}

O projeto de pesquisa foi submetido ao Comitê de Ética e Pesquisa em maio de 2017, sendo aprovado em outubro, momento em que comecei a realizar as entrevistas em campo, iniciando a fase de coleta de dados. Elegi como principais instrumentos para coleta de dados a observação participante e as entrevistas semiestruturadas. Realizei visitas semanalmente às colônias de pescadores, com o consentimento dos líderes. Geralmente, as visitas aconteciam nos finais de semana, 
durante o turno da manhã, quando os pescadores estavam presentes. A amostra foi construída por meio da metodologia conhecida como "bola de neve". Esta forma de amostragem consiste na identificação, pelo pesquisador, de um ou mais colaboradores que possam ser entrevistados primeiro e que, por sua vez, indiquem outros para participar (BAILEY, 1982); (BALDIN; MUNHOZ, 2011).

O roteiro de entrevistas se estruturou a partir de três eixos: o primeiro dedicado à história de vida do pescador, que é a caracterização individual do sujeito, sua experiência como pescador, detalhes familiares, vantagens e desvantagens de ser pescador artesanal na baía de Guanabara; o segundo abordou o trabalho na pesca artesanal da baía de Guanabara; e o terceiro eixo relacionou-se aos conflitos ambientais e à violência envolvendo os pescadores, explorando os maiores problemas que o pescador enfrenta na realização do seu trabalho, medos, confrontos com a indústria petroquímica e tipos de violência já sofridos.

Quanto ao número de participantes da pesquisa, foram entrevistados 20 pescadores artesanais, pertencentes às colônias Z-8, Z-9, Z-10 e Z-11, pescadores independentes, ou seja, pescadores que não fazem parte de nenhuma organização de pescadores (colônia ou associação) e pescadores pertencentes à Associação de Pescadores de Tubiacanga. Todas as entrevistas foram gravadas em áudio e posteriormente transcritas.

As entrevistas tiveram durações variadas, de 48 minutos a duas horas. Algumas foram interrompidas em momentos de emoção, para alimentação, necessidades fisiológicas e até mesmo trabalho. Após a coleta dos dados, dediquei-me à transcrição das entrevistas e à análise dos dados.

\section{RESULTADOS E DISCUSSÃO}

A baía de Guanabara é cercada por mais de 12000 indústrias, tanto na costa metropolitana, quanto na sua bacia de drenagem (FEEMA, 1998; LIMA, 2016). Nem um terço dessas indústrias possui um sistema de tratamento eficiente de seus efluentes, lançando diuturnamente nas águas da baía diversas substâncias tóxicas (343 kg/dia), como óleos, graxas e metais pesados (10,9 kg/dia) (CRUZ, 2007). Os rios que deságuam nas águas da baía estão, em sua maioria, contaminados por diversos agentes impactantes, como esgoto doméstico sem tratamento e esgoto oriundo de indústrias contendo mercúrio $(\mathrm{Hg})$ e chumbo $(\mathrm{Pb})$ (ANSELMO, 2011; RODRIGUES, 2011).

Os relatos dos pescadores entrevistados indicaram que a indústria de petróleo e petroquímica, com presença ostensiva na baía de Guanabara, produz várias formas de violência contra os pescadores artesanais, com destaque a: 1) ocupação do território de pesca, gerando uma 
crescente desterritorialização; 2) expansão das atividades industriais com impacto em áreas protegidas e territórios pesqueiros, como é o caso do COMPERJ; 3) degradação ambiental; 4) ameaças, atentados, assassinatos e a permanente luta e amor pelo ofício.

\section{1) OCUPAÇÃO DO TERRITÓRIO DE PESCA}

Há várias ações que as indústrias de petróleo e petroquímica executam para desterritorializar os pescadores na baía de Guanabara. Uma delas é a ampliação das redes de ductos submersos, que são responsáveis pelo bombeamento de petróleo e gás. Segundo a NORMAM-03 010833, os pescadores devem manter distância dos ductos, gerando uma limitação espacial no espelho d'água.

Os ductos também causam poluição térmica, elevando a temperatura da água, alterando as características físico-químicas, sendo mais um fator de diminuição de espécies de peixes capturados. Há ainda ferragens que são utilizadas na fixação desses ductos, que se tornam "agarradores" para as redes dos pescadores, causando muitos prejuízos financeiros, pois rasgam a trama da rede (TOMAZ; SANTOS, 2016). Some-se a isto o ruído causado pela passagem das substâncias no interior das tubulações, que contribui para espantar os peixes.

A indústria petroquímica atrapalha muita coisa... É muito bate estaca, muita tubulação, aqueles tubos ali eles não estão parados, eles estão trabalhando, os jatos de óleo, que passa ali por dentro ali, é a mesma coisa que estar aqui em cima, o peixe não encosta. Eles atrapalham, a Petrobras está atrapalhando o pescador na baía de Guanabara toda! Está acabando com tudo, estão tomando conta de tudo, então não tem como... Não tem jeito... (Pescador Carlos)

Outro fator de desterritorialização apontado pelos pescadores foi a movimentação das lanchas de apoio offshore, que não respeitam as regras de navegação, "atropelando" as redes dos pescadores, mesmo quando estão devidamente sinalizadas, agravando os problemas financeiros, pois a perda de um petrecho traz prejuízos econômicos num ambiente cada vez mais difícil de se trabalhar.

Essas lanchas que passam a noite, quando a gente está pescando, elas não querem nem saber, essas da Petrobras. Mesmo nós usando as boias sinalizadores, estamos sinalizados eles não querem nem saber, passam no meio das redes de sacanagem, só para cortar a nossa rede, entendeu? Ai uma banda da rede vai para um lado a outra vai para o outro (Pescador Orlando).

Sobre essa temática, entrevistei um pescador que, bastante emocionado, nos revelou que existem outras nuances acerca da falta de fiscalização nas águas da baía de Guanabara, no que se refere às regras de navegação e à falta de respeito por conta dos navios supply que trabalham para a indústria petroquímica. 
Teve uma vez que o navio da EMAC atropelou o nosso barco e mandou a gente para o fundo, aí fomos para o fundo da água... Eles não respeitam o pescador artesanal, não! A indústria do petróleo quer acabar com a gente! (Pescador Eric - Pescador Independente)

A segurança das instalações petroquímicas, conforme determina a NORMAM-03-0108, deve ser executada pela Marinha do Brasil ou por empresas de segurança privada. Todavia, há relatos de pescadores sobre a existência de uma espécie de milícia que serve às indústrias, cujos integrantes não se caracterizam como militares, nem tampouco como vigilantes de segurança ostensiva. Segundo os pescadores, suas ações costumam ser violentas e já foram denunciadas à Secretaria de Segurança Pública do Estado do Rio de Janeiro.

Esses homens que são da segurança da indústria petroquímica pertencem à Marinha e a empresas de segurança privada. Eles ficam descaracterizados, dentro das embarcações ou dos rebocadores. Alguns ficam patrulhando a área em lanchas descaracterizadas. Nós não sabemos quando nem de onde eles vão nos atacar. Eles atiram e ninguém os identifica! Eles não usam uniforme que possa os identificar. Diversos policiais possuem essas denúncias na mão, inclusive o Secretário de Segurança Pública do Estado do Rio de Janeiro (Pescador Ramiro).

Em Magé, Ilha do Governador, praia de Ramos e grande parte de São Gonçalo, muitas áreas de exclusão pesqueira foram estabelecidas em virtude das instalações das indústrias de petróleo e petroquímica. Incluem-se nesta categoria os ductos submersos e a própria ponte Rio-Niterói. Segundo as NORMAMs, as plataformas de petróleo e edificações petroquímicas gozam de proteção de 500 metros, diferente dos 200 metros das instalações militares. Estas zonas de exclusão têm influenciado sobremaneira o modo de vida e subsistência dos pescadores na baía de Guanabara (DIEGUES, 2000; LOPES, 2013), como relata o pescador Ramiro.

Cada terminal da REDUC cria uma área de segurança de 200 a 500 metros, isso quer dizer que, nós temos uma área de exclusão pesqueira de 200 a 500 metros por terminal. O pescador não pode passar, não pode fundear, ele não pode trabalhar ali (Pescador Ramiro).

As áreas de segurança impostas pelas NORMAMs impedem que esses homens e mulheres tenham acesso aos recursos pesqueiros, afetando sua renda familiar. Neste sentido, os pescadores também lembraram da zona de exclusão de pesca do rio Suruí, que corta a colônia de pescadores Z-9, em Magé. Relataram que empresas ligadas à indústria petroquímica edificaram às margens do rio, causando assoreamento e destruição da mata ciliar. Em virtude das obras, o pescador artesanal passou a ter dificuldade de navegação.

Zborowski (2008) afirma que as zonas de exclusão podem ser descritas como permanentes, quando acarretadas pela construção de 
uma barreira física permanente, a exemplo das refinarias de petróleo; ou temporárias, que são as que permanecem em determinado local, durante um período de tempo, como as dragagens, por exemplo. Tal fato pode ser observado na narrativa do pescador Roberto:

Aí, eles querem fazer no Rio Suruí um sistema de "siga e pare" e a gente não concorda com isso. Eles vão fazer uma obra e parar o pescador. Você para e desliga o motor, nisso, quando você liga de novo, você gasta mais combustível, e isso é por sua conta. Aí voltou, a boca do Rio Suruí, como muitos rios está assoreado, aí se passar da hora, você fica preso ali, não consegue sair e quem está lá fora não consegue entrar. Então, quem vai pagar o dano, somos nós? Errado! Direito de ir e vir! Pode ser a pé, pode ser de barco, eu vou passar! (Pescador Roberto).

Equipamentos, produtos e materiais de vários tipos também são descartados de forma irresponsável pela indústria petroquímica, em especial, os navios de apoio às operações. Essas embarcações abandonadas na baía de Guanabara, muitas vezes servem de esconderijo para pessoas mal-intencionadas, que utilizam esses espaços para práticas delituosas. Tem-se ainda o problema da acumulação da água da chuva, o que acaba transformando essas embarcações em criadouros de mosquitos capazes de transmitir diversas doenças. Além disso, essas embarcações, muitas vezes são abandonadas com grande quantidade de óleo combustível e lubrificante em seu interior, podendo vazar e contaminar a água.

Segundo a Coordenadoria Integrada de Combate aos Crimes Ambientais (CICCA), da Secretaria Estadual do Ambiente, há mais de 150 embarcações abandonadas nestas condições, todavia, a falta de fiscalização torna muito difícil que seus donos sejam localizados e punidos.

A instalação de empreendimentos da indústria de petróleo e petroquímica na região da baía de Guanabara acarreta a intensificação do uso do território e compromete permanentemente o modo de vida dos pescadores artesanais, que muitas vezes abandonam a atividade ou deslocam-se para outros locais de pesca, geralmente mais distantes dos locais habituais de trabalho. Esse fenômeno chama-se continuum colonial (MENDONÇA, 2017, p. 66), que é a expressão mundial de colonialidade, cuja consequência direta é o deslocamento compulsório ou a ameaça das comunidades tradicionais.

\section{2) EXPANSÃO DAS INDÚSTRIAS DE PETRÓLEO E PETROQUÍMICA: O COMPERJ}

O modelo de desenvolvimento pautado na exploração do petróleo justifica a ampliação dos sistemas de produção, com a criação de grandes instalações, como o Complexo Petroquímico do Estado do Rio de Janeiro (COMPERJ), que está sendo construído próximo aos 
manguezais da Área de Proteção Ambiental (APA) de Guapimirim. Esse empreendimento é tido como o maior investimento individual da história da Petrobras, sendo criado através do Plano de Aceleração do Crescimento (PAC), no âmbito do governo federal. A função deste grande empreendimento é a produção de substâncias derivadas do petróleo, resinas plásticas, além do próprio refino do óleo cru (SOARES, 2012; MAIA, 2014). Como o COMPERJ se localiza às margens da baía de Guanabara, muito próximo a uma APA e manguezais, os pescadores artesanais narram suas preocupações acerca do empreendimento, apontando não só os riscos ambientais de um vazamento, mas também o problema da desterritorialização, uma vez que os casos de desapropriações de casas são comuns da região, inclusive, com forte influência de políticos, conforme nos revela o senhor Roberto:

Segundo estão falando, as obras do COMPERJ vão voltar agora. Eles fizeram uma licitação para ver como vai ser feito e tem uma semana ou duas semanas para mostrar os detalhes da obra, de como vai ser feito... Um deputado, um tal de Wando... Mostrou ali em Suruí onde geralmente... Tem as desapropriações. Se você for embora aqui por dentro, você vai ver uma parte... Por dentro aqui, logo depois tem uma ponte que eles fizeram uma obra para passar com uns ductos por cima, umas 16 linhas se não me engano, só que ela não tem estrutura para isso, aí só vão passar três linhas e as outras vão passar por baixo (Pescador Roberto).

Além do espaço ocupado em Itaboraí, onde está o COMPERJ, foi construído o Arco Metropolitano, que serve de apoio logístico, interligando diversos municípios da região metropolitana do Rio de Janeiro. Percebi nas entrevistas que há uma certa "má vontade" dos órgãos fiscalizadores em regular as atividades da pesca industrial, do COMPERJ e das embarcações Offshore, que não sofrem as mesmas sanções e fiscalizações que os pescadores artesanais.

Tinha que ter uma vistoria boa, uma fiscalização boa, por parte do IBAMA dentro da baía de Guanabara, fiscalizar as traineiras, combater pelo menos as traineiras de pescar na beirada, por que elas têm que pescar três milhas afastadas da costa e aqui na beirada não dá três milhas... $\mathrm{E} o$ COMPERJ? Será que o IBAMA não enxerga o que o COMPERJ faz aqui dentro? (Pescador Carlos).

Os pescadores artesanais reagem diante da crescente ocupação da baía de Guanabara pelos grandes empreendimentos petroquímicos, que diminuem a qualidade ambiental, gerando além da escassez do pescado, áreas de exclusão pesqueira. Promovem "barqueatas" (atos pacíficos utilizando suas próprias embarcações de pesca) e manifestações em frente aos prédios da Petrobras, localizada no Centro do Rio de Janeiro. Também solicitam a intervenção do Ministério Público Federal através de ações civis.

Então fizemos uma barqueata, pois a empresa comprou meia dúzia de pescadores mancomunada com meia dúzia de pescadores de lá, junto 
com o pessoal do COMPERJ, deixou todos os outros pescadores de fora. Então a barqueata foi contra isso que estava acontecendo. Denunciamos aquilo, tinha mais de cem barcos de pescadores (Pescador Marcos).

Diante desta realidade, que se perpetua ao longo de muitos anos, as propostas políticas do Estado para os pescadores artesanais parecem ir na contramão das suas necessidades, beneficiando o capital, através de um modelo de desenvolvimento excludente e degradante. Parece haver uma clara associação entre os interesses de certos grupos políticos e os impactos ambientais ocasionados pelo COMPERJ.

Os políticos e autoridades na minha visão, eles protegem o ambiente sujo, para poder manter o salário deles, para poder justificar o que ele se propôs a fazer, que é cuidar do meio ambiente, mas eles estão é cuidando da poluição, eles falam que não podemos pescar em área de proteção ambiental, só que são áreas totalmente assoreadas, né? Olha o COMPERJ aí! Olha lá aquela região! Toda degradada! (Pescador Miguel).

Com relação ao descaso político, outros pescadores nos revelam a falta de ações públicas na região da colônia de pescadores a que são filiados. Eles nos relatam que para o desembarque do pescado, faz-se necessária uma ponte para facilitar a logística da pescaria. Eles nos contam que diversos políticos comparecem na colônia nos períodos que antecedem as eleições, entretanto, quando conseguem se eleger/reeleger, não cumprem o prometido, deixando os pescadores na mesma situação.

A gente precisa de ajuda e está cheio de empresas lá dentro do COMPERJ que estão acabando com a gente e não tem uma contrapartida para cá! Aí você vai nas colônias da região dos lagos, a realidade é totalmente diferente da nossa, mas... Lá é muito melhor que aqui, as empresas ajudam, a prefeitura ajuda, lá eles têm ajuda. Aqui não temos ajuda de ninguém! (Pescador Roberto).

A Petrobras, ao anunciar a construção do COMPERJ como o maior investimento da história da estatal, com a promessa de inserir o Brasil em uma época de riqueza, prosperidade e desenvolvimento, tornou-se alvo de um dos maiores escândalos financeiros envolvendo o Estado. A corrupção e o desvio de verbas públicas têm como consequência, dentre tantas, a precarização das condições de vida e trabalho dos pescadores artesanais.

\section{3) DEGRADAÇÃO AMBIENTAL}

A violência dos processos de desterritorialização é intensificada pela degradação ambiental causada pelas indústrias de petróleo e petroquímica. Durante o estudo os pescadores artesanais destacaram diferentes tipos de degradação, com destaque para a poluição sonora e despejo de efluentes. Destacam-se também a omissão do poder público, 
a falta de fiscalização dos agentes poluidores e os crescentes casos de corrupção.

Segundo os pescadores, a poluição sonora é produzida pela movimentação das embarcações na água, pela passagem de produtos químicos nos ductos e também pelos testes de prospecção sísmica (que consistem na emissão de ondas sonoras capazes de atravessar a lâmina d'água, entrando até $15 \mathrm{~km}$ no solo submarino, com o objetivo de descobrir se naquele local existe ou não petróleo). Segundo os pescadores entrevistados, a poluição sonora afugenta os peixes e prejudica enormemente o trabalho.

O pessoal fala: Mas o navio fica ali parado... Eles não ficam! Eles ficam ali fundeados eles ficam fazendo as manobras deles, fazendo as manutenções dos ductos que estão ali em baixo. Você vai ali e vê bonitinho. [...] Os peixes que vinham para reproduzir aqui dentro, não vem mais e quando vem, vem muito pouco, então, não está dando... (Pescador Roberto).

Um dos pescadores entrevistados nos revela o quão diverso era o ecossistema na baía de Guanabara num passado não muito distante, em que ele pescava com seu pai e a pesca era farta. Todavia, o pescador relata que tal fartura não é mais perceptível, devido aos efluentes vindos das empresas que margeiam a baía de Guanabara, em especial aquelas que fazem uso de derivados de petróleo. O pescador relata também o uso de "tintas envenenadas", que são utilizadas como camada passivadora nas tubulações submersas, para evitar a bioincrustação de organismos marinhos, resultando no desaparecimento de espécies marinhas.

A marinha não está vendo que as grandes empresas estão imprensando o pescador, não estão vendo que o pescador artesanal está morrendo? Veja só que acontece lá na REEDUC, os pescadores que vivem da pesca do caranguejo estão morrendo, porque aquilo lá está cheio de poluição, cheio de óleo, cheio de lixo! Então, o pescador que vive do caranguejo, estão morrendo de fome! (Pescador Negrete - Associação de Pescadores).

Rosa e Mattos (2010) afirmam que a diminuição do pescado, sejam peixes ou caranguejos, está intrinsecamente relacionada à degradação dos ecossistemas, fato que força os pescadores a irem cada vez mais longe para conseguir o sustento de cada dia. Segundo os pescadores, o acidente de 18 de janeiro de 2000 piorou muito as condições para a pesca na baía de Guanabara. Houve um derramamento de 5,8 toneladas de petróleo, que atingiu um raio de 40 quilômetros na baía de Guanabara, contaminando praias, manguezais, estuários, costões rochosos, assim como toda a fauna a e flora da região. $\mathrm{O}$ acidente aconteceu por uma falha no oleoduto PE-II, impactando grande parte da vida marinha da baía de Guanabara, incluindo as praias, manguezais, ilhas, costões e estuários. 
Rapaz... Até 2000 a pesca aqui na baía era muito boa! De 2000 para cá, depois que derramou aquele óleo na baía de Guanabara, veio piorando a cada ano que passa. Não tem pescado, não existe mais... Um peixe que você pescava com 700 metros de rede, hoje a gente sai com 1500 metros de rede e não consegue pegar uma caixa de peixe. E quando você pescava com 700 panos de rede, você pescava era 200 quilos, 300 quilos de peixe. Hoje você vai com 700 panos de rede e só pega mesmo o peixe para você levar para casa para almoçar ou jantar... (Pescador Carlos).

Ainda, segundo os relatos, os efeitos do acidente de 2000 são sentidos até os dias de hoje. Segundo os pescadores, o óleo cru derramado no acidente ainda se faz presente em alguns pontos da baía, impossibilitando a recuperação dos ecossistemas nos quais os peixes, invertebrados e moluscos, se reproduzem. Pude perceber na narrativa dos pescadores uma grande tristeza pelos danos à baia, assim como indignação com o descaso da Petrobras, responsável pelo desastre.

[...] poxa os peixes vinham aqui, agora tem muita lama com óleo no fundo, não nasce nada, nem o mangue... Tem muita dificuldade de nascer. Nós já temos a dificuldade do vazamento de óleo da Petrobras... E até hoje isso reflete na pesca. Eles dizem que está limpa, o IBAMA diz... De 2000 para cá, teve uma deterioração enorme aqui, uma dificuldade por causa dessa poluição (Pescador Francisco).

Segundo o pescador Figueiredo, além dos problemas remanescentes do derramamento de óleo do ano de 2000, a pesca também tem sido afetada pela presença de traineiras de capacidade industrial, vindas de fora da baía de Guanabara. Os pescadores alegam que estas embarcações acabam pegando o pouco que resta dos peixes comerciáveis remanescentes na região. Ainda, de acordo com o pescador, os danos ambientais foram tantos que a diversidade ecológica na baía se encontra severamente ameaçada, assim como, os pescadores artesanais que possuem seu estilo de vida ligado diretamente ao ambiente saudável e equilibrado.

Não tem mais nada para pescar! Está acabando e os barcos traineiras, passando balão estão pegando tudo! E também com esse óleo do vazamento de 2000... Eu acho que a baía de Guanabara está morrendo... E os pescadores estão pedindo socorro! Estão morrendo junto com a baía! (Pescador Figueiredo).

Em se tratando da responsabilidade civil sobre o crime ambiental, os pescadores acreditam que devido ao grande poder econômico, assim como à elevada influência política da multinacional, os julgamentos são sempre favoráveis à ré (Petrobras), haja vista que os pescadores artesanais não gozam do mesmo prestígio daqueles que detêm o poder econômico, equivalente ao seu poder de interferência no âmbito ambiental e social, influenciando, inclusive, as decisões judiciais, conforme nos relatam alguns pescadores. 
As nossas autoridades, hoje, da justiça, ela é muito... Aliada, muito aliada, as empresas como a Petrobras por exemplo, nós temos um processo aqui, que está desde o ano 2000 correndo, né? Esse processo foi julgado em primeira instância favorável para nós, pescadores. A Petrobras recorreu de tudo quanto foi lado e na segunda instância, perdemos. Eu percebo que a primeira instância julga, mas quando se vai para a segunda... Ali se perde... (Pescador Marcos).

Após dez anos da ação civil movida contra a Petrobras, o crime foi prescrito e a petroquímica não foi punida, nem tampouco houve indenização em favor dos pescadores atingidos. Tais conflitos são pano de fundo para um problema que envolve a sobrevivência de um povo tradicional e a produção de alimentos e energia para a metrópole.

\section{4) AMEAÇAS, ATENTADOS, ASSASSINATOS E A PERMANENTE LUTA E AMOR PELO OFÍCIO}

Verifiquei que durante as entrevistas que há preocupação dos entrevistados quando a temática "violência", principalmente quando se trata de violência cometida pela indústria petroquímica. Tal fato é completamente compreensível, pois os pescadores estão cotidianamente realizando suas atividades laborais próximo às instalações petroquímicas. Há vários relatos de agressão. O pescador Ramiro, por exemplo, relata que os seguranças patrimoniais da indústria petroquímica realizam disparos de arma de fogo nos barcos dos pescadores, com o intuito de acertar o motor e parar as embarcações, causando-lhes prejuízos financeiros. Este pescador, que nos conta sua história, diz que para proteger seus barcos muitos pescadores colocam-se na frente das armas e acabam pagando um preço caro, pois os seguranças não deixam de atirar por conta disso.

Teve um pescador que colocou a mão na frente do motor, pois eles dão tiro nos motores para danificar a parar nossos barcos, pois eles querem nos inutilizar. O tiro lhe amputou um dedo, que foi rapidamente colocado dentro da caixa com gelo, utilizada para conservar os peixes, e outro dedo ficou pendurado. Ele foi levado para o Hospital Paulino Werneck e os médicos conseguirem reimplantar o dedo amputado, mas que ficou pendurado, ele perdeu, o apelido dele era Tainha. O outro pescador tomou um tiro no braço e outro no peito. Ficou no hospital com "dreno" por vários dias. O tiro entrou na perna "saiu rasgando" até sair pelas nádegas dele. Ele se chamava Nelsinho (Pescador Ramiro).

Pude perceber que esses pescadores vitimados pela violência na região da baía raramente denunciam esses atos, uma vez que, devido à morosidade judicial, os crimes dificilmente serão solucionados. Eles falam ainda sobre pescadores engajados na causa ambiental, que desaparecem sem motivo plausível. 
Eu já vi meus amigos pescadores aparecem mortos... Enforcados, amarrados... Já tive amigos que morreram aqui na baía de Guanabara, teve um que amarraram ele com uma pedra e jogaram ele dentro d'água... Parece que o nó se soltou e ele flutuou... Parece que ele estava no lugar errado e na hora errada. Aqui na baía tem muito contrabando de armas, drogas, bebidas... Aqui tem de tudo (Pescador Negrete).

Vi também que alguns pescadores não se aproximam das plataformas de petróleo nem dos navios por terem medo de sofrerem algum tipo de violência:

Se se aproximar, vai ser embargado, tenho medo de ser sabotado por alguma coisa! Tem maluco para tudo, amigo! A gente pensa logo: vai sabotar alguma coisa. Eles acham que nós somos terroristas, mas nós só queremos ir ali para pegar o pescado. Não pode se aproximar muito não, se for de noite, eles "largam o aço!" Todas as firmas fazem isso, não é só a Petrobras, não! Não pode se aproximar muito não, amigo! (Pescador Paulo).

Outro pescador nos relata caso semelhante, com relação à aproximação das instalações da indústria petroquímica, quando estão pescando:

Tem a Shell também que não deixa a gente encostar, eles vêm logo em cima e mandam a gente se afastar, quando a gente vai ali nós conseguimos matar um peixinho melhorado, mas a Shell não deixa... Tem uns caras armados que mandam a gente se afastar... Como a gente não é doido a gente mete o pé de lá rapidinho (Pescador Cassio - Associação de Pescadores).

O pescador seguinte nos fala que quando não são as ameaças de efetuarem disparos de arma de fogo, são os xingamentos e insultos, proferidos pelos agentes de segurança das petroquímicas: "Você não pode encostar um pouquinho na Shell que o cara já vem gritando e xingando: Sai daí seu merda! Área inflamável! Não pode! Aí você não pode pescar" (Pescador Jacemir).

A Associação de Homens e Mulheres do Mar (AHOMAR) é uma das associações com maior representatividade na região hidrográfica da baía de Guanabara. Trata-se de uma associação que reúne pescadores e coletores artesanais, assim como outras entidades de pesca, as chamadas associações (co)irmãs, cuja finalidade é a resistência aos conflitos e injustiças ambientais a que estão expostos na baía de Guanabara, em função de suas profissões e modos de vida (CHAVES, 2011). Diversos casos de violências foram relatados pelos pescadores ligados à AHOMAR, chegando também a serem publicados em jornais ${ }^{4}$ de grande circulação.

Pelo menos seis vezes, a sede da AHOMAR foi alvo de disparos de arma de fogo. Eu já escapei de dois outros atentados, um na minha casa e outro na praia, foi quando eu percebi ser um alvo em potencial, pois eu era visto como agitador por qualificar e alertar de certa forma meus companheiros pescadores (Pescador Ramiro). 
Outro pescador relata que além de conhecer casos de pescadores desaparecidos, há ainda os que são assassinatos e as informações não são apuradas devido à omissão do Estado. "Eu já tive amigos, inclusive aqui da colônia que sumiram misteriosamente, como o Paulinho... Ele sumiu... Teve o Cané, o nome dele era Hélio, esse foi morto aqui na baía. Sem falar os que morrem por aí, que a gente não sabe o motivo..." (Pescador Negrete).

Apesar dos casos de violência ligados à indústria do petróleo e petroquímica, notei entre os pescadores coragem e desejo de continuar a viver no território da baía de Guanabara.

Por que ninguém vai tirar o direito da gente, não! Já fizeram uma vez e eu botei para quebrar! Juntei bastante gente... E, essa obra, desses ductos é para passar petróleo, gás, água... Eu tenho vídeos que eu filmei na época da obra, dos barris dentro do mangue e depois quem ficou com o prejuízo fomos nós! A gente tem que andar em zigue e zague com o barco... Aqui pode, aqui não pode... Quem não entende fica encalhado (Pescador Roberto).

Concluímos que os entrevistados ao se engajarem na luta buscam a garantia dos direitos dos pescadores artesanais da baía de Guanabara. Buscam o direito de viverem de acordo com suas tradições e crenças, mantendo as suas características identitárias, além de se fazerem representar pelas suas colônias e associações.

\section{CONSIDERAÇÕES FINAIS}

O objetivo deste artigo foi investigar como a violência e os conflitos ambientais interferem no trabalho do pescador artesanal, explorando a configuração das injustiças ambientais na baía de Guanabara. Procurei caracterizar os conflitos ambientais e os casos de violência envolvendo pescadores, identificando os sujeitos, tempos e espaços. Ainda busquei estabelecer conexões entre os casos de violência relatados pelos pescadores, o modelo econômico vigente e as políticas públicas para a baía de Guanabara.

Quanto aos casos de violência que registrei ao longo do estudo, estes revelam que sua gênese está fortemente relacionada ao avanço das atividades econômicas sobre os locais de pesca e coleta tradicionalmente utilizados pelos pescadores. Ocorre uma desterritorialização quando esses trabalhadores são forçados a alterar suas práticas cotidianas em virtude dos interesses do Estado e do capital, especialmente aos interesses da indústria do petróleo e petroquímica. Notei a existência de uma multiterritorialidade (HAESBAERT, 2007), de configuração complexa, onde estão inseridos os pescadores artesanais, a Marinha do Brasil, as indústrias e demais organizações e indivíduos que atuam na baía de Guanabara, tanto no entorno como no espelho d'água, cujas relações são marcadas por conflitos, que muitas vezes resultam em danos à vida e até mesmo à morte física do pescador artesanal. 
Defendo a tese de que os pescadores artesanais da baía de Guanabara sofrem uma violência bioétnica, cujas consequências vão desde a aniquilação dos ecossistemas até o epistemicídio dos grupos tradicionais, incluindo diversas formas de aniquilação cultural, laboral e existencial desses homens e mulheres. Segundo o estudo, a peculiaridade das relações entre os pescadores artesanais e o processo de metropolização é o que subjaz a violência bioétnica na baía de Guanabara, seja pela poluição das águas, desaparecimento do pescado, modificações de hábitos, agressões, assassinatos, invisibilidade social e todas as formas de aniquilação empreendidas contra o pescador e seu território.

O conceito de violência bioétnica que ora proponho pode ser aplicado a outras situações, como o desastre ocorrido em 05 de novembro de 2015, quando houve o rompimento da barragem de Fundão, pertencente à mineradora Samarco Mineração S/A ${ }^{5}$. Este é considerado o maior desastre ambiental do país, pois o material que vazou da barragem chegou ao mar, poluindo o Rio Doce, impactando boa parte do estado de Minas Gerais, Espírito Santo e chegando até a Bahia. O acidente ainda comprometeu o abastecimento de água potável para diversas regiões, onde aconteceu o transbordo das substâncias.

Neste sentido, as políticas públicas para a baía de Guanabara não podem excluir os pescadores artesanais. Questões de ordem pública devem ser discutidas e implementadas com a participação desses grupos, garantindo seu direito ao trabalho e à vida. O território é o elo que une os pescadores artesanais e seu legado ancestral, o que lhes confere o direito à livre manifestação cultural, ao estilo de vida, suas crenças e tradições. É o território que proporciona a certeza, dentro de uma realidade contemporânea, que o pescador artesanal tem a oportunidade de vivenciar as dificuldades e as virtudes do mundo moderno. A perda de território de pesca é uma forma cruel de agressão, que devido à intensa ocupação territorial e ao adensamento populacional desenfreado, tornam, cada vez mais, a baía de Guanabara uma das baías metropolitanas mais poluídas e violentas do mundo.

Concluo, portanto, que os pescadores artesanais da baía de Guanabara também possuem direito à vida, a viver em um ambiente seguro e ter liberdade de trabalho e de cultivar suas tradições e costumes, conforme o preconiza o artigo III da Declaração Universal dos Direitos Humanos ${ }^{6}$. Ademais, ninguém deve ser submetido à tortura, maus tratos como castigos cruéis e desumanos, nem mesmo ser privado de sua liberdade sem motivo plausível, de acordo com o artigo V da mesma Declaração.

Sendo assim, as situações de violência, as quais trazem riscos e impedimentos à vida dos pescadores artesanais, devem ser confrontadas através de interseções de luta e resistência para a legitimação desses homens e mulheres que buscam o seu reconhecimento social na região da baía de Guanabara. 


\section{NOTAS}

1. O vazamento de 1,293 milhões de litros de óleo in natura na baía de Guanabara, em 18/01/2000, gerou graves prejuízos para seu ecossistema e, por conseguinte, para toda a população que dele se abastece, contaminando o espelho d'água, as areias e os costões rochosos.

2. Segundo Marés (2002), direito socioambiental se caracteriza por um novo paradigma de direitos da cidadania, passando pelos direitos individuais e indo muito além. Não se trata da soma linear dos direitos sociais e ambientais previstos no ordenamento jurídico do País, mas de um outro conjunto resultante da leitura integrada desses direitos, pautada pela tolerância entre os povos e pela busca do desenvolvimento comum e sustentável.

3. NORMAM-03 0108, Marinha do Brasil, Diretoria de Portos e Costas, Áreas de Segurança, com ênfase a letra "a". Não é permitido o tráfego e fundeio de embarcações nas seguintes áreas consideradas de segurança:

a) a menos de duzentos (200) metros das instalações militares;

b) áreas próximas às usinas hidrelétricas, termoelétricas e nucleoelétricas, cujos limites serão fixados e divulgados pelas concessionárias responsáveis pelo reservatório de água, em coordenação com o $\mathrm{CP}, \mathrm{DL}$ ou $\mathrm{AG}$ da área;

c) fundeadouros de navios mercantes;

d) canais de acesso aos portos;

e) proximidades das instalações do porto;

f) a menos de 500 (quinhentos) metros das plataformas de petróleo;

g) áreas especiais nos prazos determinados em Avisos aos Navegantes; $\mathrm{e}$

h) as áreas adjacentes às praias, reservadas para os banhistas, conforme estabelecido no item anterior (MARINHA DO BRASIL - DIRETORIA DE PORTOS E COSTAS, 2017).

4. Jornal Extra - Pescador que lutava contra obra da Petrobras é morto em Magé. Disponível em: <https://extra.globo.com/casos-de-policia/pescador-que-lutava-contra-obra-da-petrobras-morto-em-mage-401780.html >. Acesso em: 28 ago. 2018.

5. Jornal o Globo. Maior desastre ambiental do Brasil, Tragédia de Mariana deixou 19 mortos. Disponível em: <https://acervo.oglobo.globo.com/em-destaque/maior-desastre-ambiental-do-brasil-tragedia-de-mariana-deixou-19-mortos-20208009>. Acesso em: 05 nov. 2018.

6. Disponível em: <https://www.unicef.org/brazil/pt/resources_10133.html>. Acesso em: 28 nov. 2020.

\section{REFERÊNCIAS}

ACSELRAD, Henri. Justiça ambiental: ação coletiva e estratégias argumentativas. In: ACSELRAD, Henri; HERCULANO, Selene; PÁDUA, José Augusto. Justiça ambiental e cidadania. Rio de Janeiro: Relume Dumará, 2004.

ACSELRAD, Henri; MELLO, Cecília Campello Amaral; BEZERRA, Gustavo das Neves. O queé justiça ambiental. Rio de Janeiro: Garamond, 2009. AMADOR, Elmo da Silva. Assoreamento da Baía de Guanabara, Subsídios para a Elaboração do Plano Diretor de Controle. Rio de Janeiro: Instituto de Geociências da UFRJ, 1997. 
AMADOR, Elmo da Silva. Roteiro de visita à Baía de Guanabara. In: Educação Ambiental: especialização e capacitação em educação para gestão ambiental. Rio de Janeiro: Gráfica UERJ, 2001. p. 127-147. v. I.

ANSELMO, Márcio Belleti. Desenvolvimento de um Sistema de Mistura para Tratamentos de Efluentes em Depósitos de Resíduos. 2011. 68 f. Dissertação (Mestrado). Pontífice Universidade Católica, Rio de Janeiro, 2011.

BAILEY, Kenneth. Methods of Social Research. New York: The Free Press, 1982.

BALDIN, Nelma; MUNHOZ, Elzira. Educação Ambiental Comunitária: uma experiência com a técnica de pesquisa snowball (bola de neve). Revista Eletrônica Mestrado Educação Ambiental. v. 27, p. 46-60, 2011.

BRASIL. Congresso. Senado. Decreto $N^{\circ} 6.040$, de 7 de fevereiro de 2007, institui a Política Nacional de Desenvolvimento Sustentável dos Povos e Comunidades Tradicionais. Diário Oficial [da] República Federativa do Brasil, Brasília, DF, 08 de fevereiro de 2007.

CALDEIRA, Teresa Pires do Rio. Cidade de muros: crime, segregação e cidadania em São Paulo. Trad. Franklin de Oliveira e Henrique Monteiro. São Paulo: Editora 34/EDUSP, 2000.

CHAVES, Carla Maria Stella Ramôa da Silva. Mapeamento participativo da pesca artesanal da Baía de Guanabara. 2011. 187 f. Dissertação (Mestrado em Geografia) - Programa de Pós-Graduação em Geografia, Instituto de Geociências, Universidade Federal do Rio de Janeiro, Rio de Janeiro, 2011. CONSELHO PASTORAL DOS PESCADORES (Org.): TOMÁZ, Alzení de Freitas; SANTOS, Gilmar. Conflitos Socioambientaise Violações de Direitos Humanos em Comunidades Tradicionais Pesqueiras no Brasil. Brasília: CPP, 2016. 104p.

CRUZ, Luciano Corado. Educação Ambiental e Politicas Públicas: a Baía de Guanabara e o Boto-cinza. 2007. 114 f. Dissertação (Mestrado em Ciência Ambiental) - Universidade Federal Fluminense, Rio de Janeiro, 2007.

DIEGUES, Antônio Carlos. (Org.). Os saberes tradicionais e a biodiversidade no Brasil. São Paulo: MMA/NUPAUB, 2000.

FEEMA. FUNDAÇÃO ESTADUAL DE ENGENHARIA DO MEIO AMBIENTE. Qualidade de Água da Baía de Guanabara (1990/1997). Programa de Despoluição da Baía de Guanabara/Programas Ambientais Complementares. Rio de Janeiro: FEEMA, 1998. v. 1.

FUKS, Mário. Conflitos ambientais no Rio de Janeiro: ação e debate nas arenas públicas. Rio de Janeiro: Editora da UFRJ, 2001. 243 p.

HAESBAERT, Rogério. O Mito da Desterritorialização: do "fim dos territórios" à multiterritorialidade. $3^{\text {a }}$ ed. Rio de Janeiro: Bertrand Brasil, 2007.

HERCULANO, Selene; PACHECO, Tânia. (Org.). Racismo Ambiental: I Seminário Brasileiro sobre Racismo Ambiental. Rio de Janeiro: FASE, 2006.

LIMA, Elizabeth Cristina da Rocha. Qualidade de Água da Baía de Guanabara e Saneamento: Uma Abordagem Sistêmica. 2016. 183 f. Tese (Doutorado) COPPE, Universidade Federal do Rio de Janeiro, Rio de Janeiro, 2016. 
LITTLE, Paul Eliot. A etnografia dos conflitos sócio-ambientais: bases metodológicas e empíricas. In: I ENCONTRO dA Associação NACIONAL de Pós-Graduação e Pesquisa em Ambiente e Sociedade. Anais... Indaiatuba, 2004.

LOPES, Alissandra Pinheiro. Territorialidades em conflito na Baía de Sepetiba, Rio de Janeiro, Brasil: estudo de caso dos conflitos entre os pescadores artesanais e o porto da Companhia Siderúrgica do Atlântico (ThyssenKrupp CSA). 2013. 109 f. Dissertação (Mestrado em Ciência Ambiental) - Programa de Pós-Graduação em Ciência Ambiental, Universidade de São Paulo, São Paulo, 2013.

MAIA, Aline Borghoff. Ministério Público, Megaempreendimentos e Conflitos Socioambientais: A atuação no litígio entre pescadores artesanais e a indústria do petróleo na Baía de Guanabara-RJ. 2014. 156 f. Dissertação (Mestrado) - Instituto de Ciências Humanas e Sociais, Universidade Federal Rural do Rio de Janeiro, Rio de Janeiro, 2014.

MARTINEZ-ALIER, Joan. Justiça ambiental e distribuição ecológica de conflitos. In: FERREIRA, Leila da Costa (Org.). A sociologia no horizonte do século XXI. São Paulo: Boitempo, 1997. p. 122-135.

MENDONÇA, Bartolomeu Rodrigues. Continuum Colonial: Colonialidade (=modernidade), Empreendimentos Capitalistas, Deslocamentos Compulsórios e Escravos da República no Estado do Maranhão, Brasil. 2017. 313 f. Tese de (Doutorado) - Programa de Pós-graduação em Ciências Sociais/CCH, Universidade Federal do Maranhão, 2017.

PELLOW, David. Social inequalities and environmental conflicts. Horizontes Antropológicos, Porto Alegre, ano 12, n. 25, p. 15-29, jan./jun. 2006.

PORTO, Marcelo Firpo de Souza. Uma ecologia política dos riscos: princípios para integrarmos o local e o global na promoção da saúde e da justiça ambiental. Rio de Janeiro: Editora Fiocruz, 2007.

RODRIGUES, Silvio Cesar Alves. Comunidade Tradicional ou Zona de Sacrifício? A Disputa pela Ilha da Madeira, Cenário de Conflito, Regulação e Intervenção! In: Horizontes de Brasil Escenarios, Intercambios Y Diversidad. 1 ed. Espanha: AGMS Editora, 2011.

ROSA, Márcia Ferreira Mendes; MATTOS, Ubirajara Aluízio de Oliveira. A saúde e os riscos dos pescadores e catadores de caranguejo da Baía de Guanabara. Revista Ciência é Saúde Coletiva, v. 15, supl. 1, p.1543-1552, jun. 2010.

ROSA, Márcia Ferreira Mendes; MATTOS, Ubirajara Aluízio de Oliveira; BRANQUINHO, Fátima Teresa Braga. Baía de Guanabara: A Degradação e o Trabalho dos Pescadores Artesanais. (Geo)Políticas do Meio Ambiente, Gestão dos Recursos e Sustentabilidades. I Congresso Brasileiro de Geografia Política, Geopolítica e Gestão do Território, 2014, Rio de Janeiro. Anais... Porto Alegre: Editora Letra1; Rio de Janeiro: REBRAGEO, 2014. p. 408-414. 
SILVA, Sueli Batista da. O Serviço Social frente à questão da violência doméstica: a realidade social revelada nas ações judiciais da vara de Infância, da Juventude e do idoso da Comarca da Capital do Rio de Janeiro. 2005. 85 f. Dissertação (Mestrado) - Pontifícia Universidade Católica, Rio de Janeiro, 2005.

SOARES, David Gonçalves. Pescadores e Petrobras: ação coletiva e justiça ambiental na Baía de Guanabara. 2012.201 f. Tese (Doutorado) - Programa de Pós-Graduação em Sociologia e Antropologia, RUFRJ/IFCS, Rio de Janeiro, 2012.

VALENTIN, Jean Louiz; TENENBAUM, Denise Rivera; BONECKER, Ana Cristina; BONECKER, Sérgio Luiz Costa; NOGUEIRA, Catarina; VILLAC, Maria Célia. O Sistema Planctônico da Baía de Guanabara: Síntese do Conhecimento. Ecologia dos Ambientes Costeiros do Estado do Rio de Janeiro. Series Oecologia Brasiliensis, Rio de Janeiro, PPGE-UFRJ, v. VII, p. 35-39, 1999.

ZBOROWSKI, Marina Barbosa. Conflitos ambientais na Baía de Sepetiba: o caso dos pescadores atingidos pelo processo de implantação do complexo industrial da Companhia Siderúrgica do Atlântico (ThyssenKrupp CSA). 2008. 254 f. Dissertação (Mestrado em Psicossociologia de Comunidades e Ecologia Social) - Instituto de Psicologia, Universidade Federal do Rio de Janeiro, Rio de Janeiro, 2008.

ZHOURI, Andréa; LASCHEFSKI, Klemens. (Org.). Desenvolvimento e conflitos ambientais. Belo Horizonte: Editora UFMG, 2010. 484 p. 